\title{
(Não) é só uma gripezinha: argumentação e realidade forjada nos pronunciamentos de Jair Bolsonaro sobre a covid-19
}

\author{
Alexandre Marques Silva \\ Doutor em Letras pela Universidade de São Paulo (USP), Brasil \\ (a) alexandremarques@usp.br (1) orcid.org/0000-0002-8719-7306
}

Resumo: Toda ação política mediada pelo uso da linguagem, invariavelmente, instaura a perspectiva de seu agente. Como parte desse processo, a construção dos objetos de discurso pode ser entendida como uma estratégia crucial para que o líder político consiga forjar uma versão da realidade suficientemente coerente a ponto de persuadir sua audiência. Assim, este artigo objetiva analisar as estratégias discursivo-argumentativas empregadas por Jair Bolsonaro em referência à covid-19 em pronunciamentos públicos e em postagens no Twitter. Com fundamento nos pressupostos teóricos da Nova Retórica, da ACD e da Sociocognição, identificamos que essa doença, discursivamente recategorizada, passou a integrar o grande rol de inimigos a serem combatidos - ao menos discursivamente - por Bolsonaro.

Palavras-chave: Argumentação. Discurso Político. Covid-19. Bolsonaro.

\begin{abstract}
Every political action mediated by the use of language, invariably, establishes the perspective of its agent. As part of this process, the construction of speech objects can be understood as a crucial strategy for the political leader to forge a version of reality that is sufficiently coherent to persuade his audience. Thus, this article aims to analyze the discursive-argumentative strategies employed by Jair Bolsonaro in reference to covid19 in public speeches and in some posts on Twitter. Based on the theoretical assumptions of New Rhetoric, CDA and Sociocognition, we identified that this disease, discursively recategorized, became part of the great list of enemies to be fought - at least discursively - by Bolsonaro.
\end{abstract}

Keywords: Argumentation. Political Speech. Covid-19. Bolsonaro. 


\section{Introdução}

Até o presente momento, a história da humanidade havia sido marcada por duas grandes pandemias': a peste bubônica, no século XIV, e a gripe espanhola, no início do século XX, as quais, juntas, foram responsáveis pela morte de aproximadamente 700 milhões de pessoas. Atualmente, vivemos uma espécie de terceira onda, com os casos de covid-19, que já somam 6.152.160 de casos confirmados e 371.700 óbitos no mundo. No Brasil, são 514.992 os doentes confirmados, com 29.341 mortes, com pico de 1.039 óbitos por dia, superando os Estados Unidos, que possui a maior taxa de infectados em âmbito mundial ${ }^{2}$.

Diante de um cenário como esse, a maioria dos líderes políticos de todo o mundo têm se mobilizado para combater o avanço da covid-19 por meio de ações que vão do isolamento social, passando pela aplicação de multas àqueles que descumpram tal determinação, até práticas como o lockdown. No entanto, Brasil e Estados Unidos, presididos, respectivamente, por Jair Bolsonaro e Donald Trump, vêm adotando medidas controversas em relação ao que determinam as autoridades internacionais de saúde, posicionando-se abertamente contrários ao isolamento social amplo. No caso brasileiro, Bolsonaro defende abertura de serviços não essenciais (como igrejas, academias e salões de cabeleireiro) e a adoção de um isolamento vertical, apenas para indivíduos que façam parte do grupo de risco ${ }^{3}$. Em comum, ambos os presidentes defendem o uso de cloroquina e hidroxicloroquina no combate à doença, mesmo havendo constantes alertas da comunidade científica sobre a falta de comprovação da eficácia dos fármacos nesses casos.

Dadas as dimensões, não apenas sanitárias, mas também econômicas e sociais dessa pandemia, estudiosos de diversas áreas estão se dedicando a investigá-la sincronicamente, de modo a oferecer subsídios teóricos e práticos para o tratamento/combate à doença, com o desenvolvimento de respiradores, medicamentos e vacinas, por exemplo, e a compreensão dela,

\footnotetext{
1 Além das mencionadas, historicamente, também são consideradas pandemias a Peste de Justiniano, ocorrida no Império Bizantino, em 541 d.C., e a Gripe Russa, em 1580, que causou a morte de 1 milhão de pessoas, da Rússia ao Rio de Janeiro, segundo dados da época.

${ }^{2}$ Disponível em: https://en.wikipedia.org/wiki/Template:COVID-19_pandemic_data. Acesso em: 01 jun. 2020

${ }^{3}$ De acordo com a Organização Mundial da Saúde, pertencem ao grupo de risco indivíduos que portem doenças crônicas como diabetes e hipertensão, asma e/ou tenham mais de 60 anos.
} 
analisando os efeitos que determinados discursos podem provocar em termos de construção de realidades, como é o caso deste artigo.

Partindo do princípio de que palavras desencadeiam ações e de que o discurso político, em especial o presidencialista, tem, muitas vezes, caráter iminentemente performativo, selecionamos trechos de pronunciamentos públicos de Jair Bolsonaro, bem como três publicações feitas por ele em sua conta pessoal no Twitter para identificar os procedimentos de construção do objeto de discurso covid-19. Como suporte teórico-metodológico, recorremos à Análise Crítica do Discurso (ACD), à Nova Retórica, da escola de Bruxelas, e à Sociocognição.

1. "Sou o Messias, mas não faço milagre": discurso político, dominação carismática e poder

Em sociedades democráticas, os espaços públicos - todos eles - são ontologicamente locais em que, por meio de discursos, debatem-se temas de relevância à vida social, pratica-se a argumentação, constroem-se e (de)formam-se valores. Nesse campo simbólico, em que conquistar o poder para governar a sociedade é o fim último, os lugares legitimados para que esses discursos sejam produzidos (e disseminados) são restritos, privilégio de poucos. Assim, a assimetria de acesso a esses locais tem produzido no cenário político brasileiro contemporâneo a disseminação de valores diretamente responsáveis pela polarização político-ideológica do País. Não se trata de uma disputa estritamente política, o que se observa, entretanto, pelos discursos oficiais do atual presidente da república, Jair Messias Bolsonaro, entre outros temas delicados e controversos, é a prática recorrente de desprestígio do conhecimento científico (das humanidades em especial) e da intelectualidade de modo mais amplo, o que tem impactado tanto nas políticas internas quanto no âmbito das relações internacionais.

A alternância do poder é condição essencial a toda sociedade democrática e engendra, de tempos em tempos, o embate ideológico entre partidos políticos e entre indivíduos que os representam ou que com eles se identificam. Desse modo, é relevante retomarmos episódios recentes da história brasileira para ilustrarmos o quanto o domínio da palavra, no sentido de forjar realidades, é fundamental para a conquista do poder político. 
Nas últimas eleições presidenciais, em função de uma série de manobras políticas, houve significativa polarização ideológica do Brasil, sintetizada basicamente na figura de dois candidatos: Bolsonaro e Lula (posteriormente Haddad). De um lado, estavam aqueles que defendiam a renovação política, a "reconstrução do país", sintetizados na figura de Jair Bolsonaro (filiado ao PSL, à época), o qual defendia medidas como: reforma administrativa para redução de gastos; combate à corrupção; privatização e extinção de empresas estatais, corte de verbas para ONGs de direitos humanos, veto a propostas de liberação do aborto; pagamento de $13^{\circ}$ salário a beneficiários do Bolsa Família; posse de armas a "cidadãos de bem"; tipificação do MST (Movimento dos Sem Terra) como terrorismo; proibição da adoção de crianças por casais homossexuais; criação de colégios militares etc. ${ }^{4}$. De outro, posicionavam-se os que desejam a continuidade do governo (anterior ao impeachment de Dilma Rousseff), que idealizavam na figura de Lula a retomada de projetos que o marcaram nos períodos em que fora presidente. No entanto, ele se tornou réu em um processo de corrupção e lavagem de dinheiro, que culminou com sua prisão durante a campanha eleitoral. Assim, com o impedimento de Lula, Fernando Haddad foi o nome escolhido pelo PT para concorrer ao pleito de 2018. Entre suas propostas, destacam-se: estímulo às cooperativas de crédito e à inserção de novos bancos no cenário econômico nacional; investimento dos recursos do pré-sal em saúde e educação; interrupção de privatizações; isenção de imposto de renda para quem recebe até 5 salários mínimos; reforma tributária para reduzir os impostos dos mais pobres e compensar a queda de arrecadação cobrando dos mais ricos; compra de alimentos orgânicos para a merenda escolar em todo o Brasil; convênios entre as escolas federais e estaduais para melhorar o ensino médio nos estados, entre outras ${ }^{5}$.

Ainda que apresentados de forma sintetizada, é possível observar que os projetos políticos dos candidatos que disputaram o segundo turno das eleições presidenciais de 2018 eram bastante distintos, o que promoveu discussões acaloradas, sobretudo por seus apoiadores, nas redes sociais (com disseminação irrestrita de fake News, inclusive), aumentando ainda mais a

4 O plano de governo de Bolsonaro pode ser consultado integralmente em: http://divulgacandcontas.tse.jus.br/candidaturas/oficial/2018/BR/BR/2022802018/280000614517//pro posta_1534284632231.pdf. Acesso em: 20 mai. 2020.

5 O plano de governo de Haddad pode ser consultado integralmente em: https://drive.google.com/file/d/1el6Zqs4voXqzbmfHVSgNNrppNwzLJE5x/view. Acesso em: 20 mai. 2020 
dicotomização do debate e criando um cenário maniqueísta, principalmente após a prisão de Lula: apoiar o PT (ou seu candidato) rapidamente converteuse em uma associação direta com a defesa da corrupção, de ladrões que “extirpavam a nação, impedindo-a de prosperar”. Essa narrativa ganhou força e, associada a outros fatores, como a tentativa de assassinato sofrida por Bolsonaro, em Minas Gerais, criou um contexto favorável à sua eleição em 2018. Eleito o presidente do Brasil, é importante compreendermos como se constitui o campo no qual ele exerce seu poder, no caso, o político.

O termo "política", derivado da palavra grega pólis - designativa de cidade e, por extensão, de tudo o que diz respeito ao espaço urbano - foi expandido graças à obra Política, de Aristóteles. Durante séculos, esse conceito foi empregado em trabalhos cujo objetivo era analisar as relações humanas em sua esfera de atuação mais legítima: a sociedade. Segundo Aristóteles (1998, p. 15):

É evidente que o Estado existe por natureza e que o homem é por natureza animal social e, mais do que todas as abelhas e todo animal vive em sociedade. Porque a natureza nada faz em vão: ora, só o homem, entre os animais, possui razão. A linguagem serve para demonstrar o útil e o danoso e, por isso também o justo e o injusto, o que é próprio dos homens a respeito dos outros animais: ter somente ele sentido do bem e do mal, do justo e do injusto.

O fato de o homem ser, como bem definiu Aristóteles, "um animal social", implica que os vínculos estabelecidos entre os indivíduos em uma sociedade sejam atravessados por relações assimétricas de poder. Nesse sentido, a ação política ganha destaque por ordenar a vida social e estabelecer regras que assegurem o bem comum. Todavia, tais práticas somente são acolhidas quando partem de uma instância legitimada política e socialmente. (MARQUES SILVA, 2010)

O poder político, nesse contexto, pode ser entendido como uma relação social dicotômica de mando e obediência. Charaudeau (2008), ao identificar a complexidade relativa à questão do poder e da legitimidade política, defende que é possível reconhecer a interação, mediada pela linguagem, entre ação política, responsável por organizar as relações de força e de interesses que se estabelecem na sociedade; as instâncias, as partes implicadas nessas ações; e os valores, em nome dos quais a ação é realizada. Ainda, de acordo com Charaudeau (2008), é necessário à transformação da influência em "poder de ação" que o sujeito colocado na condição de dominado reconheça a 
autoridade daquele que o domina, estabelecendo-se entre ambos uma relação de poder, a qual só pode ser realizada, pacificamente, quando a situação se reveste de um discurso ideológico que justifique a assimetria existente entre esses atores sociais. Assim, é fundamental aos objetivos deste trabalho que observemos como essa relação é forjada nos/pelos discursos de Jair Bolsonaro.

Durante a campanha eleitoral e nos pronunciamentos públicos que tem realizado como presidente da república, é relevante observar que, em parte do processo de construção da realidade sob sua perspectiva ideológica, Bolsonaro se apropria de valores pretensamente coletivos (como defesa da família a qualquer custo, por exemplo) “[...] em nome de um ideal supostamente compartilhado por certo número de indivíduos - mesmo se minoritário - que têm a necessidade de manter-se sob uma aparência de aprovação popular [...]" (CHARAUDEAU, 2008, p. 20), ou seja, trata-se de um simulacro por meio qual se forja uma realidade de aprovação e/ou que corrobore a narrativa criada pelo discurso do referido político. Essa relação é evidente, por exemplo, quando se observa que, apesar de recentemente haverem aumentado de forma alarmante os casos confirmados de covid-19 (com mais de 1.000 óbitos por dia no Brasil ${ }^{6}$ ) Bolsonaro vem se posicionando contrariamente a decisões de organismos nacionais e internacionais, como o próprio Ministério da Saúde e a Organização Mundial da Saúde (OMS), e ainda encontra apoio em um pequeno estrato da população (27\%, segundo dados da Pesquisa XP/Ipespe ${ }^{7}$ ).

Um dos caminhos para compreendermos a motivação desse apoio encontra-se nos tipos de dominação definidos por Weber na obra Economia e sociedade: fundamentos da sociologia compreensiva, originalmente publicada entre 1920 e 1921. Para esse autor: “A ‘dominação', como conceito mais geral e sem referência a algum conteúdo concreto, é um dos elementos mais importantes da ação social. [...]. Todas as áreas da ação social, sem exceção, mostram-se profundamente influenciadas por complexos de dominação" (WEBER, 2004 [1920-1921], p. 187).

\footnotetext{
6 Dados disponíveis em: https://g1.globo.com/bemestar/coronavirus/noticia/2020/05/22/casos-decoronavirus-e-numero-de-mortes-no-brasil-em-22-de-maio.ghtml. Acesso em: 24 mai. 2020.

7 Disponível em: https://www.poder36o.com.br/pesquisas/aprovacao-de-bolsonaro-cai-4-pontosdepois-da-demissao-de-moro-diz-xp/. Acesso em: 20 mai. 2020.
} 
Ao tratar da dominação, o sociólogo alemão descreve três tipos legítimos: 1. carismática, considerada uma forma primitiva de poder, anterior ao surgimento de leis, assenta-se sobre os valores pessoais do líder (o ethos para a retórica), caracterizado como um messias, profeta, herói ou demagogo, cujas ações são motivadas por sua vontade particular, prática comum em regimes totalitários. De modo geral, a dominação carismática, por ser instável, funda-se no autoritarismo, na constante manutenção e reafirmação das qualidades do líder, no cuidado que ele deve ter em parecer sempre mais carismático que seus apoiadores/apóstolos, a fim de evitar amotinamentos ou o surgimento de novas lideranças mais carismáticas que possam colocar em xeque a legitimidade de seu poder. Em síntese, quando se trata de dominação carismática: "A obediência a uma pessoa se dá devido às suas qualidades pessoais. [...] Não há carreiras e não é requerida formação profissional por parte do "portador" do carisma e de seus ajudantes." (WILD, s/d) ${ }^{8}$. 2. tradicional, apoiada fundamentalmente em valores da tradição (como a família), entendida como a instituição social mais forte e, amiúde, incontestável. A administração da sociedade ocorre de forma patriarcal (representada por um chefe soberano, pai de família) e com base em fidelidades, não em leis, realizada por pessoas do círculo próximo ao líder, de modo a estreitar as relações entre as esferas pública e privada. "Na dominação tradicional, não existe nada, além da própria tradição, para reger a conduta das pessoas, se por um lado o senhor é limitado pela tradição, por outro, naquilo que ela não especifica, ele pode decidir à vontade, de acordo com seus princípios [...]"9 . 3. legal, aquele que ocupa o lugar de poder deve exercê-lo, conforme as prerrogativas dos estatutos, das leis, assim a obediência se descentra da figura do líder e assenta-se nas regras, as quais determinam a quem e com que extensão se deve obedecer. Trata-se de um tipo de poder mais estável porque está fundado em normas que são criadas e modificados sob amparo legal.

Ainda na obra de 1921-1992, Weber defende que a dominação é um tipo especial de poder, no sentido de que ela tem a capacidade de impor a

\footnotetext{
${ }^{8}$ Não nos é possível localizar cada referência na página uma vez que o documento encontra-se em formato HTML.

9 FRAGA, Vitor Galvão. Os três tipos de dominação legítima de Max Weber. Disponível em: https://jus.com.br/artigos/25863/os-tres-tipos-de-dominacao-legitima-de-max-weber\#_ftn1. Acesso em: 20 mai. 2020.
} 
terceiros a vontade própria (do líder), entanto, considerando as particularidades de uma sociedade como a brasileira, essa vontade precisa ser discursivizada como coletiva e estar (ainda que aparentemente) atrelada a valores democráticos para ser aceita. Assim, o auditório a quem se destinam discursos com essa característica deve ser persuadido de modo a reconhecer no político uma autoridade capaz de realizar aquilo que propõe em nome da comunidade, estabelecendo-se, pois, uma relação assimétrica de poder em que as partes "mantêm entre si relações de força que constroem simultaneamente o vínculo social” (CHARAUDEAU, 2008, p. 17).

O vínculo social a que Charaudeau (2008) faz referência funda-se em acordos, tácitos em alguns casos, segundo os quais o representante político reveste-se de certa autoridade e os cidadãos alienam-se de alguns direitos, como o de decisão sobre o destino do orçamento público, por exemplo, que passam a ser exercidos por um corpo especializado de ministros e secretários definindo pelo líder, em consonância com critérios que sejam convenientes a seu projeto de governo. Tal concepção de poder político "resulta dialeticamente de dois componentes da atividade humana: o do debate de ideias no vasto campo do espaço público, lugar onde se trocam opiniões; o do fazer político no campo mais restrito do espaço político onde se tomam decisões e se instituem atos" (CHARAUDEAU, 2008, p. 22, itálicos do autor). Nesse sentido, é importante considerar que essas duas instâncias legitimam-se mutuamente e ambas se definem por relações de força intermediadas pela linguagem e pela ação. No âmbito do debate das ideias, há o predomínio da linguagem, constituindo-se, por excelência, como arena de lutas discursivas em que estratégias como manipulações, ameaças e promessas são recorrentes no processo de conquista da legitimidade das opiniões dos oponentes. Por sua vez, o fazer político refere-se ao exercício do poder por meio da ação, de modo a assegurar que os cidadãos reconheçam-na como legítima e compreendam que não a respeitar/obedecer implica sanções. Em síntese: “A palavra política deve se debater entre uma verdade do dizer e uma verdade do fazer, uma verdade da ação que se manifesta por meio de uma palavra de decisão e uma verdade da discussão que se manifesta mediante uma palavra de persuasão (ordem da razão) e/ou sedução (ordem da paixão)" (CHARAUDEAU, 2008, p. 23, itálicos do autor). 
Figura 1 - Capa do Plano de Governo de Jair Bolsonaro, 2018.

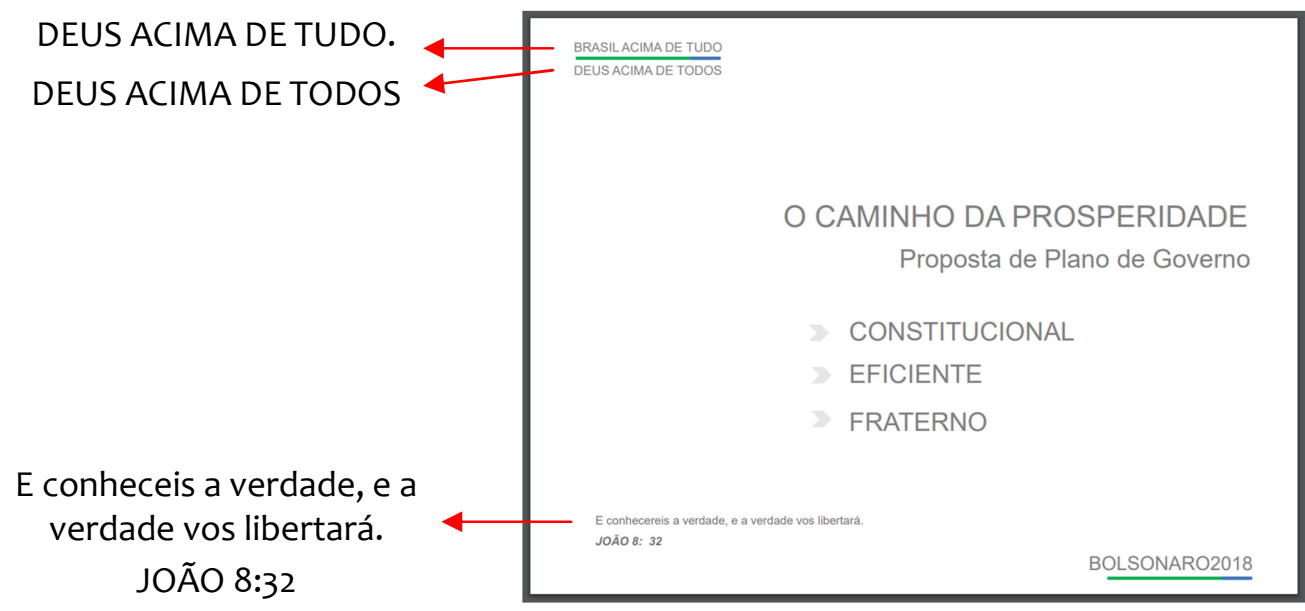

Disponível em: https://bit.ly/2ZtafTY. Acesso em: 20 mai. 2020.

Preliminarmente, sem nos aprofundarmos nas análises, é possível afirmar que o modus operandi de Bolsonaro permite identificá-lo como líder cuja dominação oscila entre a carismática e a tradicional. Para além da coincidência entre seu codinome (Messias) e o ethos de messias ${ }^{10}$ que ele construiu ao longo da campanha eleitoral (principalmente), com uma clara associação de seu plano de governo ao discurso religioso - como se observa nos elementos destacados na Figura 1 - em seus discursos, Bolsonaro tem apelado frequentemente a estratégias de patemização e, sobretudo, de construção de inimigos que o impediriam de agir como benemérito da nação, conforme atestam, a título de exemplo, os excertos a seguir:

[1] "Sabiam do problema do governador [do Rio de Janeiro, Wilson Witzel], que queria minha cabeça a todo custo. Que o objetivo dele é ser presidente da República, né? E para isso tinha que destruir a mim e a minha família. O tempo todo vivendo sob tensão. Possibilidade de busca e apreensão na casa de filho meu, onde provas seriam plantadas. Levantei, graças a Deus tenho amigos policiais civis e policiais militares no Rio de Janeiro, o que estava sendo armado para cima de mim. 'Moro, eu não quero que me blinde. Mas você tem a missão de não deixar eu ser chantageado'. Nunca tive sucesso para nada"

[2] "Sabia que não seria fácil. Uma coisa é você admirar uma pessoa. A outra é conviver com ela, trabalhar com ela. Hoje pela manhã, por coincidência,

\footnotetext{
${ }^{10}$ Trataremos do ethos na seção 2. "O brasileiro tem que ser estudado”: subsídios epistemológicos para a compreensão da realidade forjada.

11 Disponível em: https://g1.globo.com/jornal-nacional/noticia/2020/05/22/bolsonaro-diz-ementrevista-que-governador-do-rio-wilson-witzel-queria-a-cabeca-dele.ghtml. Acesso em: 20 mai. 2020.
} 
tomando café com alguns parlamentares, eu lhes disse: 'Hoje vocês conhecerão aquela pessoa que tem um compromisso consigo próprio, com seu ego, e não com o Brasil'. O que eu tenho ao meu lado, e sempre tive, foi o povo brasileiro. Hoje, essa pessoa vai buscar uma maneira de botar uma cunha entre eu (sic) e o povo brasileiro. Isso aconteceu há poucas horas." ${ }^{\prime 2}$

[3] "Essa imprensa lixo chamada Globo. Ou melhor, lixo dá para ser reciclado. Globo nem lixo é, porque não pode ser reciclada."’3

Os fragmentos supracitados explicitam que, em diferentes discursos, Bolsonaro recorre à mesma estratégia: evoca um elemento que, em sua narrativa, assume o papel de inimigo, seja um líder político, uma emissora de televisão ou um ex-aliado político (Sérgio Moro, no caso) que se convertem rapidamente em desafetos à proporção que o contrariam ou expõem fatos que comprometam sua imagem. Ademais, apela às emoções do auditório, em [1], ao justificar suas ações como forma de proteger o filho e quando agradece a Deus pelos amigos que tem; em [2], ao afirmar que "Sabia que não seria fácil" [a relação com Sérgio Moro] e também em "Hoje, essa pessoa vai buscar uma maneira de botar uma cunha entre eu e o povo brasileiro."; em [3], a forma como ele se refere à Globo: "Essa imprensa lixo chamada Globo." Desse modo, constroem-se discursivamente desafetos políticos que atribuem força à imagem que Bolsonaro deseja manter de si mesmo: um líder em luta incessante contra o mal: um adversário político que deseja o seu fracasso, um ex-aliado "traidor do Brasil" e a imprensa, respectivamente.

Embora tenhamos reconhecido que, de forma generalizada, a dominação praticada por Bolsonaro esteja em uma região fronteiriça entre a carismática e a tradicional, entendemos, que, no corpus selecionado para a realização deste trabalho, destaca-se a carismática. Assim, em consonância com a teoria weberiana, considerando que a dominação carismática é frágil porque se funda nas características pessoais do líder, é necessário a Bolsonaro reforçá-la constante e publicamente a fim de reafirmar a seus apoiadores que, de fato, o lugar de "predestinado" ocupado por ele requer muitos esforços e lutas frequentes contra aqueles que não desejam a prosperidade dos "cidadãos de bem", para usarmos termos do discurso bolsonarista.

12 Disponível em: https://noticias.uol.com.br/politica/ultimas-noticias/2020/04/24/leia-integra-dodiscurso-de-bolsonaro-apos-demissao-de-moro.htm. Acesso em: 20 mai. 2020.

${ }^{13}$ Disponível em: https://www.bbc.com/portuguese/brasil-52553647. Acesso em: 20 mai. 2020. 
Para Weber (2004 [1920-1921]), a dominação carismática é aquela que se exerce em função da virtude de um indivíduo que desperta em seus seguidores (ou súditos) uma devoção afetiva, oriunda de capacidades mágicas, heroísmo, poder do espírito e do discurso. Nesse sentido, "carisma” deve ser compreendido fora de seu uso corrente, já que, na perspectiva empregada pelo autor, ele está associado à ideia de que um líder deve se fazer crível. A associação de domínio carismático é de caráter comunitário, sendo aquele que ordena o "chefe". Não há, nessa concepção, o conceito racional de competência, nem o de Estado e de privilégio, sendo o "chefe" seguido pelos seus "discípulos" em função de seu carisma e de suas vocações pessoais. O sempre novo, o extracotidiano, o inaudito e o arrebatamento emotivo que esse tipo de liderança provoca constituem a força de devoção pessoal dos seguidores. A autoridade carismática é preconizada por Max Weber (2004 [1920-1921]) como uma das grandes forças revolucionárias da História. Desse modo, associar-se à figura de líder carismático possibilita a construção discursiva da realidade empreendida por Bolsonaro, pois, conforme destaca Carvalho (1999, p. 10-11):

A elaboração de um imaginário é parte integrante da legitimação de qualquer regime político. É por meio do imaginário que se podem atingir não só a cabeça, mas, de modo especial, o coração, isto é, as aspirações, os medos e as esperanças de um povo. É nele que as sociedades definem suas identidades e objetivos, definem seus inimigos, organizam seu passado, presente e futuro. $O$ imaginário social é constituído e se expressa por ideologias e utopias, sem dúvida, mas também - e é o que me interessa - por símbolos, alegorias, rituais, mitos. [...] Na medida em que tenham êxito em atingir o imaginário, podem também plasmar visões de mundo e modelar condutas. A manipulação do imaginário social é particularmente importante em momentos de mudança política e social, em momentos de redefinição de identidades coletivas.

A manipulação do imaginário social é imprescindível em situações nas quais se busca legitimar um regime político fundamentado em questões ideológicas (embora esse seja um expediente amplamente rechaçado por Bolsonaro e seus apoiadores). A partir da manipulação de ideologias é que se constroem imagens capazes de definir paradigmas de comportamento e desencadear um processo de unidade social centrada no reconhecimento de uma autoridade carismaticamente edificada, valores estes reforçados pelas estratégias argumentativas levadas a termo nos discursos do líder político. 
2. "O brasileiro tem que ser estudado": subsídios epistemológicos para a compreensão da realidade forjada

Ao nos debruçarmos sobre os pronunciamentos de Bolsonaro para identificar relações profundas entre a argumentação e seu êxito em termos de persuasão, consideramos relevante assumirmos uma postura interdisciplinar de análise e, assim, recrutarmos teorias que nos amparem na construção de um quadro de referência coerente com nossos objetivos.

Comecemos pela Análise Crítica do Discurso, cujo escopo consiste em identificar e denunciar abusos de poder. Em ACD, os discursos são tomados sempre como formas de interação situada, ou seja, como práticas sociais que sofrem coerções de ordem política, social, histórica e cultural. Assim, segundo Marques Silva (2018, p. 125):

A Análise Crítica do Discurso destaca-se entre as atuais propostas de investigação no âmbito dos estudos do discurso por apresentar como um de seus pilares a multidisciplinaridade na abordagem dos fenômenos discursivos. Nesse sentido, no intrincado processo de análise e compreensão dos discursos, agregam-se conhecimentos oriundos de distintos campos do saber, não exclusivamente circunscritos aos estudos da linguagem.

Desse modo, no que concerne aos estudos do discurso, nossa perspectiva parte da compreensão de que o uso da linguagem constitui uma prática social e uma ação sócio-historicamente situada, responsável, neste caso, em específico, pelo forjamento de realidades, e, como corolário, de sistemas de conhecimentos e de crenças. Nesse processo, a linguagem atende a demandas sociais e cognitivas, criando, por meio de símbolos linguísticos, cultural e socialmente constituídos, formas de representação cognitiva. Ademais, o uso linguístico incorpora perspectivas particulares acerca do objeto analisado, o que implica também compreensões específicas do mundo discursivizado relacionadas a distintas formas de produção e disseminação de conhecimento.

Apresentadas essas observações iniciais, salientamos a preocupação em investigar as práticas sociais e as ideologias presentes nos discursos, mediadas fundamentalmente pela cognição. Nesse sentido, os pressupostos sobre os quais se funda a $A C D$, como modelo teórico-metodológico, possibilitam o mapeamento das relações entre a performance cognitiva e os recursos 
linguísticos utilizados por Bolsonaro e aspectos da rede de práticas em que a interação discursiva se insere (MARQUES SILVA, 2018).

O segundo fundamento teórico ao qual recorremos para a consecução de nossas análises refere-se à construção dos objetos do discurso por meio dos processos de referenciação. De acordo com Marques Silva (2018, p. 161), os indivíduos, em sua tentativa de criar um universo referencial que indique ações, sentimentos, lugares, estados de espírito, pessoas, acontecimentos etc., estabelecem suas convicções e revelam o lugar discursivo que ocupam e a partir do qual enunciam seus discursos. Nessa mesma direção, Marcuschi (2007, p. 141) argumenta que "não se pretende negar o valor referencial da língua e sim de rever a maneira como se dá esse processo de referenciação. $O$ sujeito não é apenas enunciativo e sim também social e nesta ação social situada ele instaura e diz o mundo".

Com base no que postula Marcuschi (2007), depreendemos que a relação entre as "coisas do mundo" e sua discursivização não ocorre de forma transparente, direta ou objetiva e podemos, inclusive, evocar a dicotomia saussureana sobre a arbitrariedade do signo linguístico para a compreensão de que essa relação não é, nem poderia ser, inequívoca. Subjacente a ela, estão as relações de poder, as ideologias e os processos cognitivos, que atuam de maneira decisiva no modo como as "coisas do mundo" são apreendidas nas práticas discursivas e, posteriormente, convertidas em “objetos de discurso." Desse modo, todo ato de nomeação das coisas do mundo é, por sua natureza constitutiva, ideológico e limitado, pois incide sobre apenas um aspecto do objeto, operando sobre ele uma categorização que seja relevante para o projeto de dizer do enunciador. Trata-se, por conseguinte, de um processo de construção de objetos de discurso, responsável pela ênfase de determinadas características do objeto construído, o que revela não apenas uma estratégia argumentativa do enunciador, mas também quais são os valores e crenças implicadas nessa construção.

O terceiro elemento de nosso aporte refere-se à argumentação. Partimos do princípio de que a construção de sentido e a eficiência dos argumentos necessitam da existência, ainda que parcial, de valores, crenças e referências comuns entre os envolvidos no processo comunicativo. Assim, o poder de persuasão de um argumento tende a ser proporcionalmente equivalente ao grau de afinidade existente entre as ideias apresentadas pelo 
orador e aquelas em que o auditório acredita, pois, dessa forma, haverá menos assimetrias em relação aos sistemas doxológicos de ambos. Nesse sentido, não se pode desprezar que o ato linguístico, os procedimentos de construção de referências no discurso, por meio dos quais a argumentação se enuncia, e as palavras se transformam em ação, ou seja, assumem a função "fazer-fazer".

No processo de convencimento ou de persuasão de seu auditório, o orador deve, como já apontamos, organizar seu discurso em torno de provas que o torne crível, coerente e menos suscetível à contra-argumentação. Assim, de posse do conhecimento dos valores aceitos em dada comunidade, compete ao orador - o líder político nesse caso - trazer para seu discurso elementos afinados ao sistema doxológico da audiência e, para isso, pode se valer de estratégias como a patemização e o apelo ao próprio ethos, como provas. Nesse sentido, observamos que, nos discursos políticos, é necessário ao orador fazer valer seu ponto de vista como um imperativo à aquisição e/ou à manutenção do poder e, consequentemente, como possibilidade de concretização de seus projetos.

No caso dos discursos de Bolsonaro, de modo generalizado, observa-se a construção de um tipo de ethos, bastante explorado por políticos populistas ${ }^{14}$, que consiste em, discursivamente, criar uma imagem de si que se associe e, mais do que isso, que se confunda, com a de um líder predestinado, um messias, aquele que combate heroicamente todas as mazelas de que sofre o povo, conforme se observa, além do excerto [1], nos trechos destacados nos fragmentos a seguir, extraídos do discurso pronunciado pelo presidente em 25 de março de 2020:

[4] Desde quando resgatamos nossos irmãos em Wuhan, na China, em uma operação coordenada pelos ministérios da Defesa e das Relações Exteriores, surgiu para nós um sinal amarelo. Começamos a nos preparar para enfrentar o coronavírus, pois sabíamos que mais cedo ou mais tarde ele chegaria ao Brasil.

\section{[5] [...] tínhamos que conter naquele momento era o pânico, a histeria.}

[6] Sem pânico ou histeria, como venho falando desde o início, venceremos o vírus e nos orgulharemos de estar vivendo neste novo Brasil, que tem tudo, sim,

\footnotetext{
${ }^{14}$ Sobre a construção do ethos em discurso político populista, cf. A imagem por trás do mito: estratégias discursivas e construção do ethos no discurso político presidencial. Disponível em: https://www.teses.usp.br/teses/disponiveis/8/8142/tde-14092011-133813/pt-br.php. Acesso em: 28 mai. 2020.
} 
para ser uma grande Nação. Estamos juntos, cada vez mais unidos, Deus abençoe nossa pátria querida.

O excerto [6], em particular, permite-nos destacar uma característica importante dos pronunciamentos de Bolsonaro: o amalgamento entre o discurso político e o religioso, o qual, além de corroborar traços da dominação carismática, também justifica, conforme apontado por Ajzenman, Cavalcanti e Da Mata (2020), o número expressivo de evangélicos apoiadores do presidente desde o período de campanha eleitoral, cerca de $70 \%$ nessa faixa da população.

3. "E daí? Não sou coveiro": estratégias discursivo-argumentativas de construção da realidade

Segundo dados do Ministério da Sáude ${ }^{15}$, o primeiro caso de covid-19, no Brasil, foi registrado em 26 de fevereiro, em São Paulo, e, desde então, o presidente vem se pronunciando acerca dos casos e dos impactos da doença na economia, principalmente. Para a consecução das análises, observamos, sob uma perspectiva cronológica, trechos de pronunciamentos públicos (entrevistas diárias, discursos oficiais em redes de televisão e postagens no Twitter) realizados entre 06 de março e 20 de maio de 2020, de modo a identificar as estratégias utilizadas por Bolsonaro para construir discursivamente o objeto do discurso "covid-19" e as implicações desse expediente na formulação de conhecimentos acerca do coronavírus.

Na obra Simulacro e simulações, Baudrillard alerta-nos de que, em um contexto de hiper-realidade, não haveria espaço para o real nem para a verdade, já que ela estaria marcada pela liquidação de todos os referenciais, com a inevitável ressureição artificial dos sistemas de signos, os quais estariam a serviço da substituição do real por sua simulação impessoal e desterritorializada, ou seja, haveria a construção de um simulacro aplicável a qualquer indivíduo independentemente do local onde ele esteja, volatilizando, assim, toda e qualquer singularidade. Nesse sentido, entendemos que os discursos políticos, dada sua natureza de editar a realidade conforme a ideologia e os objetivos pragmáticos (em termos de adesão às teses postuladas) daquele que o pronunciam, procedem a acabamentos dessa

${ }^{15}$ Disponível em: https://www.saude.gov.br/noticias/agencia-saude/46435-brasil-confirma-primeirocaso-de-novo-coronavirus. Acesso em: 20 mai. 2020. 
realidade por meio da construção de simulacros, da manipulação de signos e de valores que lhes façam parecer (e ser) sempre a melhor (quando não a única) alternativa para a conquista do bem-estar social.

\section{1 “É só uma gripezinha": presunções sobre o desconhecido}

Em conformidade com Perelman e Olbrechts-Tyteca (1999 [1958]), compreendemos que o objetivo fundamental de toda argumentação eficaz consiste em aumentar a intensidade da adesão dos ouvintes às teses postas em discussão, de modo a desencadear neles a ação pretendida pelo orador. Nesse sentido, ação é um termo-chave para compreendermos o êxito dos discursos de Jair Bolsonaro no sentido de persuadir seus apoiadores de que o coronavírus não é grave problema com o qual devam se preocupar a ponto de permanecerem isolados.

[7] Nos últimos meses, surgiu um vírus novo. Não há motivo para pânico. (Pronunciamento de 06 mar. 2020)

[8] Obviamente, temos no momento uma crise, uma pequena crise, ou, no meu entender, muito mais fantasia a questão do coronavírus, que não é isso tudo que a grande mídia propala ou propaga pelo mundo todo. (Pronunciamento de 10 mar. 2020)

[9] Depois da facada, não vai ser uma gripezinha que vai me derrubar, não, tá ok? (Pronunciamento de 20 mar. 2020)

[10] No meu caso particular, pelo meu histórico de atleta, caso fosse contaminado pelo vírus, não precisaria me preocupar, nada sentiria ou seria, quando muito, acometido de uma gripezinha ou resfriadinho [...]. (Pronunciamento de 24 mar. 2020)

Observando os elementos destacados nos excertos acima, podemos reconstituir o processo de construção do objeto de discurso "covid-19". Inicialmente a doença é referida de forma metonímica, por meio do agente causador, o qual é concebido genericamente como um "vírus novo", em [7]. Nesse sentido, a indefinição pode ser reconhecida como estratégica por deslocar o conhecimento sobre a doença para o âmbito das presunções. Uma vez que se trata de um evento inédito, pouco ainda se sabia sobre a gravidade do coronavírus, portanto, o presidente presumiu que não haveria "motivo para pânico". Assim, atenuando-se a importância a ser dada ao problema por meio de presunções, Bolsonaro, como se observa nos demais excertos, 
recorre a eufemismos para reforçar a adesão à tese de que não se trata de uma doença grave: em [9] "Depois da facada, não vai ser uma gripezinha que vai me derrubar, não, tá ok?” e em [10] “[...] não precisaria me preocupar, nada sentiria ou seria, quando muito, acometido de uma gripezinha ou resfriadinho [...]."

Vale destacar que, em [8], a covid-19 passa a pertencer ao conjunto de crises que marcam o governo, no entanto, com uma especificidade, trata-se de "uma pequena crise, ou, no meu entender, muito mais fantasia a questão do coronavírus, que não é isso tudo que a grande mídia propala ou propaga pelo mundo todo.". Desse modo, compreendemos que os eufemismos, nesses pronunciamentos de Bolsonaro, funcionam como uma estrutura de definição retórica para o que é desconhecido. Nos casos observados, é possível reconhecer que ele se vale dessa estrutura de definição não para fornecer o sentido do termo em causa, mas para enfatizar certos aspectos de uma realidade que ele projeta/simula em relação à doença e seus desdobramentos no cenário nacional.

Além disso, os eufemismos desviam o foco da importância do problema, por meio de analogias que constroem o novo coronavírus como algo já conhecido ("resfriadinho", "gripezinha”) e para o qual já existem procedimentos médicos de prevenção e tratamento. Cabe salientar, ainda, que o emprego de formas diminutivas dos referidos termos também concorre para a mitigação da importância sobre a doença, estabelecendo, assim, um enquadramento discursivo que permite ao auditório caracterizar o desconhecido como familiar e, por conseguinte, preocupar-se menos em prevenir-se contra ele.

Essa é uma estratégia retórica de construção de objeto de discurso fundada, a um só tempo, tanto nos eufemismos quanto em analogias, as quais permitem a transferência para o novo de características do já conhecido com base em uma intersecção semântica. Por meio desses procedimentos retóricodiscursivos, a covid-19 assume, nos pronunciamentos de Bolsonaro, o status de uma doença similar a gripes e resfriados, já conhecidos pelos brasileiros. Da perspectiva da argumentação, o desconhecido é convertido em ordinário e, consequentemente, cria, no interior dessa comunidade epistêmica, um novo conhecimento (não necessariamente científico) sobre os termos 
"coronavírus" e "covid-19", favorecendo os processos de persuasão e de construção da realidade empreendidos por Bolsonaro.

3.2 "Tá com medinho de pegar o vírus?": a covid-19 como mais um inimigo a combater

De modo geral, Bolsonaro demonstra conceber os momentos de pronunciamento público como de confronto, conforme ilustra a seleção lexical utilizada por ele nos fragmentos a seguir:

[11] O vírus está aí vamos ter que enfrentá-lo, mas enfrentar como um homem, pô, não como moleque. Vamos enfrentar o vírus com a realidade, é a vida. Todos nós iremos morrer um dia. (Pronunciamento de 29 mar. 2020)

[12] Sempre afirmei que tínhamos dois problemas a resolver: o vírus e o desemprego que deveriam ser tratados simultaneamente. (Pronunciamento de 08 abr. 2020)

[13] Lamentavelmente, veio um vírus aí, todo mundo tá sofrendo, o mundo está sofrendo. Nós estamos sofrendo com mortes aqui, mas nós temos que enfrentar isso aí. (Pronunciamento de 06 mai. 2020)

Além de haver sido associado a um conhecimento compartilhado por meio da analogia: a covid-19 é como uma "gripezinha", Bolsonaro também insere esse objeto do discurso no âmbito das lutas que deve empreender para garantir o bem-estar social. Fundamentando-se na associação metafórica recorrente nos discursos políticos: "política é guerra", a doença e o vírus que a causa passam a ser concebidos como "inimigos". Assim, o espaço público converte-se em arena de batalha e compete ao presidente lutar, discursivamente, contra eles.

A covid-19, reduzida ao vírus, é introduzida, em [11], como inimigo que deve ser enfrentado por um indivíduo que aja como "homem". Nesse sentido, Bolsonaro apela para a doxa de seu auditório, mobilizando valores presumidos, tais como força, coragem, altivez, determinação, entre outros, os quais, de acordo com o senso comum, estariam tradicionalmente associados à figura masculina, de um homem adulto e responsável, em oposição à de um "moleque", que, em situações informais, indica sujeitos irresponsáveis e, por extensão, que fogem à luta.

Em [12], o "vírus" é colocado no mesmo plano de gravidade que o "desemprego", revelando a dicotomia bastante discutível relacionada às 
estratégias de combate ao coronavírus, que consistem em opor o isolamento social à preservação dos empregos daqueles que o fizerem. Em síntese: promoveu-se uma relação dialética entre salvar vidas e preservar a economia do país.

Cabe destacar, também, que é pública a admiração que Bolsonaro devota a Donald Trump, e isso se revela não apenas no alinhamento ideológico, mas, sobretudo, no modo como o primeiro emula o segundo na condução de algumas políticas públicas, como é o caso do combate ao coronavírus. Com base no tuíte a seguir, é possível reconhecer a mimese que Bolsonaro faz em relação ao discurso do presidente dos Estados Unidos nesse sentido. Em 23 de março, Donald Trump fez a seguinte publicação no Twitter:

Figura 1 - Tuíte de Trump de 23/03/2020

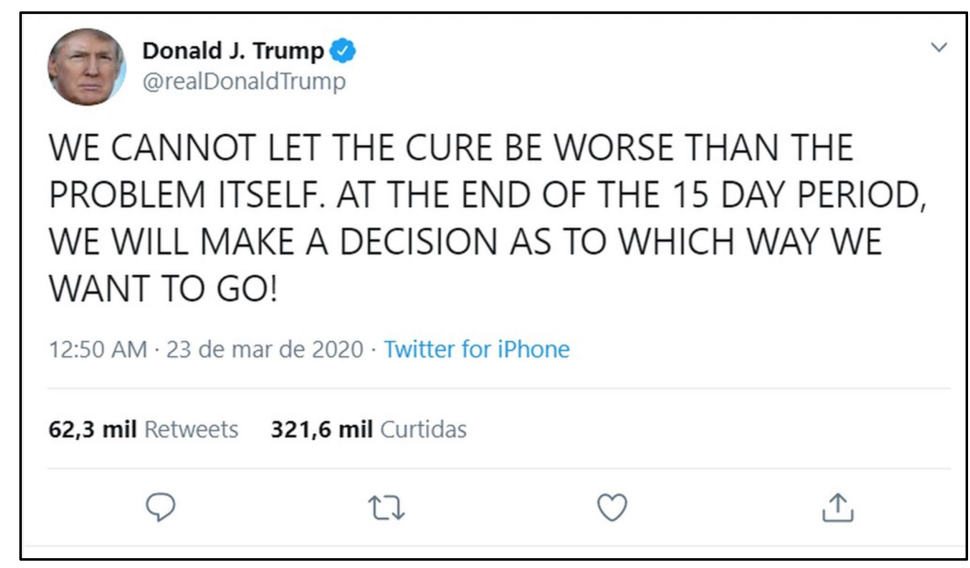

Disponível em: https://twitter.com/realDonaldTrump. Acesso em: 20 mai. $2020{ }^{16}$

Na sequência, no pronunciamento realizado em 24 de março, Bolsonaro afirma: "Brigar para que não venha desemprego como efeito colateral. Aí vai complicar mais ainda, a cura ficar pior que a doença em si”, posicionamento reforçado pela publicação de 8 de abril no Twitter:

\footnotetext{
${ }^{16}$ Tradução nossa: Não podemos deixar que a cura seja pior que o problema em si. Ao final do período de 15 dias, tomaremos uma decisão sobre o caminho que queremos seguir.
} 
Figura 2 - Tuíte de Bolsonaro de 08/04/2020

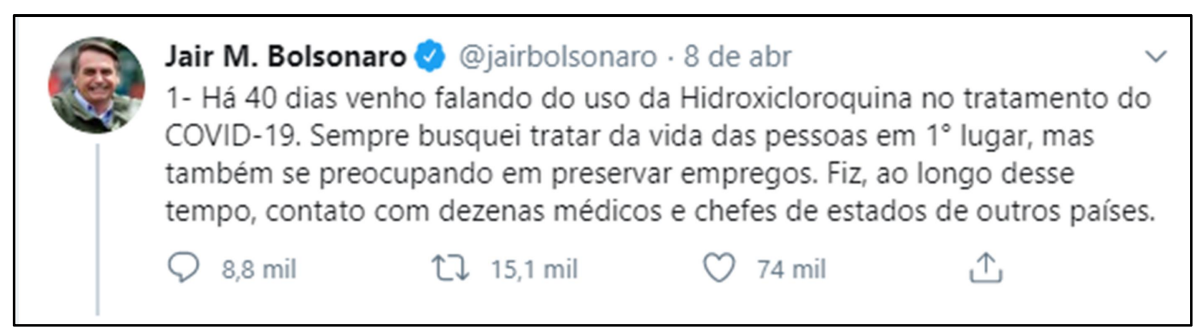

Disponível em: https://twitter.com/jairbolsonaro. Acesso em: 14 mai. 2020.

O vírus, assim, presentifica-se nos pronunciamentos como um inimigo que deve ser combatido porque impede as pessoas de viverem e de preservarem seus empregos, no entanto, destaca-se o fato de que Bolsonaro, em situações como as descritas nos excertos analisados, vale-se majoritariamente de um "nós" de referência indefinida (ele e os ministros, ele e os governadores, ele e o auditório...) e, nesse caso, entendemos se tratar de uma estratégia crucial à argumentação, pois permite a ele definir um campo de luta entre um "nós" coletivo frente a um "ele" desconhecido, como ilustrado em [13] "nós temos que enfrentar isso aí.". Assim, o uso de primeira pessoa do plural retira dele a responsabilidade exclusiva de combater o coronavírus. Não definir ao certo quem deve responder pela solução do problema permite ao orador proceder a deslocamentos - que o eximem de responsabilidade - como os que se verificam nas passagens destacadas nos seguintes fragmentos:

[14] Mas ainda o número de pessoas que morreram de $\mathrm{H} 1 \mathrm{~N} 1$ no ano passado foi na ordem de 800 pessoas. A previsão é não chegar a essa quantidade de óbitos no tocante ao coronavírus. Espero que não queiram me culpar lá na frente pela quantidade de milhões e milhões de desempregados na minha pessoa, e digo mais: brevemente o povo saberá que foi enganado por esses governadores e por grande parte da mídia nesta questão do coronavírus. (Pronunciamento de 22 mar. 2020)

[15] O Supremo decidiu que quem decide essas questões são os governadores e prefeitos então cobrem deles. Eles têm que responder. Vocês não vão botar no meu colo essa conta. (Pronunciamento de 29 abr. 2020)

Observa-se que a construção discursiva da covid-19 como um inimigo cria uma cadeia de equivalências semânticas a qual, apoiada em valores presumidos, justifica a Bolsonaro reconhecer a necessidade de combatê-lo energicamente ("como um homem"), mas sem se responsabilizar por isso, já 
que o agente da luta está diluído no uso de um "nós” coletivo, que, ambíguo, converte-se em uma lacuna preenchível do modo como cada indivíduo desejar, conforme seus valores e suas crenças.

3.3 "Todos nós iremos morrer um dia": cloroquina - a nova aliada no combate a "tudo isso que está aî"

Por fim, no processo de construção do objeto de discurso covid-19, após defini-lo, identificar quem são os responsáveis por combatê-lo, Bolsonaro, em conformidade com a estratégia de eufemização, apresenta um tratamento o qual, segundo ele, garantiria a cura da doença, mesmo sem haver comprovação científica de seus resultados, como ele mesmo reconhece em um de seus pronunciamentos: "Ainda não existe remédio contra ele [o coronavírus] com eficiência cientificamente comprovada”. (Pronunciamento de 31 mar. 2020)

[16] Agora há pouco, os profissionais do Hospital Albert Einstein me informaram que iniciaram um protocolo de pesquisa para avaliar a eficácia da cloroquina nos pacientes com covid-19. (Pronunciamento de 21 mar. 2020)

[17] Aquele remédio lá, hidroxicloroquina, tá dando certo em tudo quanto é lugar. Um estudo francês chegou para mim agora. Eu não sou médico, não. Chegou agora. (Pronunciamento de 29 mar. 2020)

\section{Figura 3 - Tuítes de Bolsonaro sobre o uso cloroquina no tratamento de covid-19}

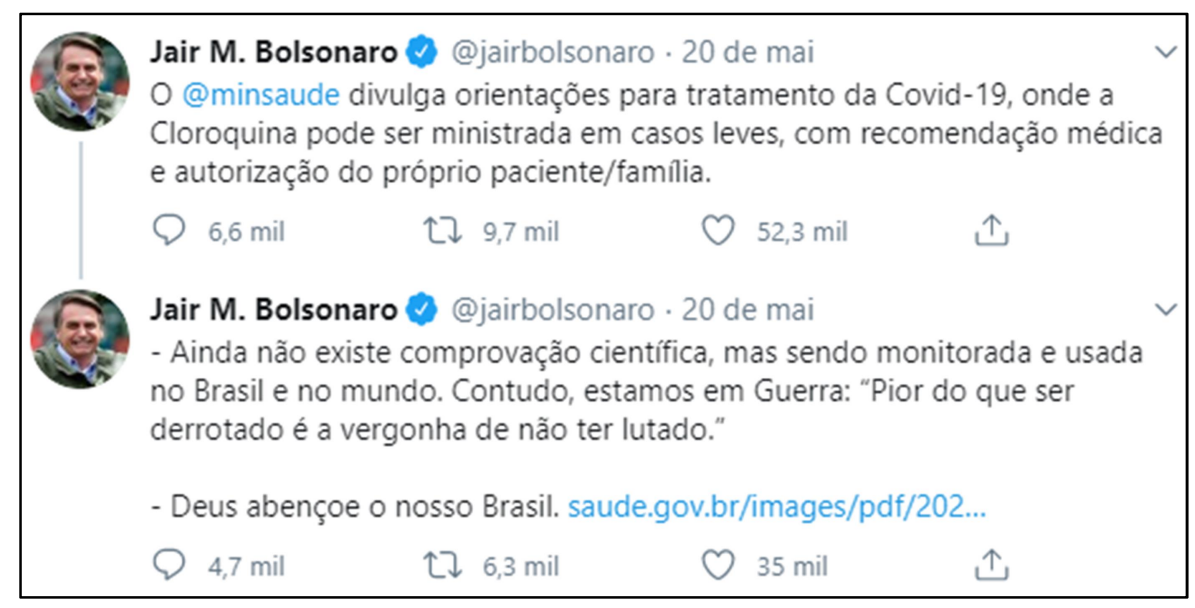

Disponível em: https://twitter.com/jairbolsonaro. Acesso em: 14 mai. 2020. 
Como líder político, espera-se que Bolsonaro (com o suporte de equipe especializada) atue no sentido de indicar à população quais procedimentos devem ser adotados para combater o inimigo. Desse modo, ainda que não tenha certeza, é preciso simular tê-la, sob o risco de comprometer seu ethos. Nesse sentido, a sequência de tuítes apresentada na Figura 2 indica que o presidente reconhece que o uso de cloroquina não é seguro, já que não há comprovação científica de seus benefícios.

Além disso, o desconhecimento de Bolsonaro quanto à eficácia daquilo que propõe como solução para o problema é reforçado pela tentativa de se valer de um argumento de autoridade, como em [16]: "[...] os profissionais do Hospital Albert Einstein me informaram que iniciaram um protocolo de pesquisa [...]". Em tese, aludir à autoridade de um hospital renomado de São Paulo seria suficiente para fortalecer o argumento do presidente em relação ao uso da cloroquina, todavia, como se observa no que ele enuncia em [17]: "Aquele remédio lá, hidroxicloroquina tá dando certo em tudo quanto é lugar.", as marcas de oralidade "lá" e "em tudo quanto é lugar”, indicam que o orador, dada a imprecisão lexical dos termos que constroem referências irrecuperáveis pelo contexto, tem pouco conhecimento sobre o medicamento, seus usos, bem como sobre sua eficácia no tratamento de covid-19.

Desse modo, a cloroquina converte-se, discursivamente, na única solução possível, uma vez que não se apresentam outras, para pôr termo aos problemas causados pelo novo inimigo da pátria.

\section{Considerações finais}

Forjar uma realidade alternativa, que esteja em conformidade com projetos políticos daqueles que ocupam posições de poder, é crucial para garantir a adesão e o apoio popular. Nesse sentido, identificamos que os pronunciamentos de Bolsonaro procedem a acabamentos da realidade, que lhe permitirem elaborar imaginários a partir dos quais ele dá forma a seus inimigos políticos.

Relativamente à construção do objeto de discurso covid-19, observamos que o presidente recorre, inicialmente, à estratégia retórica da eufemização associada a analogias, como forma de criar um novo conhecimento acerca da 
doença, associando-a a gripes e resfriados. Assim, por meio de simplificações, a covid-19 passa a ser enquadrada no rol de enfermidades conhecidas e para as quais já existem protocolos de cuidado. Há, portanto, uma redução da gravidade do problema, que se justifica, nesse caso, pela falta de conhecimentos - teóricos e práticos - sobre ele.

Na sequência, a covid-19 é discursivamente construída como mais um inimigo a ser combatido no universo da arena política. Novamente a doença é enquadrada no âmbito do já conhecido pela audiência por meio de metonimização (reduzida ao vírus) e de estruturas comparativas: ela é um problema como o é o desemprego e ambos devem ser enfrentados. Estrategicamente, em pronunciamentos cujo tema relaciona-se ao combate ao coronavírus, Bolsonaro recorre ao uso de um pronome "nós", superficialmente homogêneo, de forma a tornar difusa a referência ao(s) agente(s) responsável(is) pela ação, o que lhe permite, em alguns momentos, eximir-se dessa tarefa.

Uma vez que o inimigo se tornou conhecido e as estratégias de combate foram determinadas, foi necessário definir as armas a serem utilizadas contra ele: a cloroquina e a hidroxicloroquina. Todavia, esse não é um procedimento chancelado por estudos científicos em termos de eficiência e, por isso, ainda há severas oposições a ele, sobretudo da comunidade médica, que tem destacado os riscos à vida do uso desses medicamentos nos casos de covid-19.

Por conseguinte, como parte da estratégia de legitimação do poder por líderes que exercem dominação carismática consiste na manutenção constante dos predicados que os fazem notáveis, Bolsonaro trata de construir, em seus pronunciamentos - como eventos sócio-historicamente situados - , um simulacro, uma versão da realidade sobre a covid-19 e seus desdobramentos econômicos e sociais de modo a compartilhar um paradigma comum com sua audiência, favorecendo, assim, seu projeto de dizer e suas ações como líder político que, como "mito", ocupa um lugar para o qual foi escolhido e de onde, como "messias", atua contra "tudo isso aí". 


\section{Fontes}

BBC Brasil: As declarações de Bolsonaro na crise do coronavírus. Disponível em: https://www.youtube.com/watch?v=pDJQf-QEtF4. Acesso em: 14 de mai. 2020.

Estadão. Bolsonaro e o coronavírus: veja falas do presidente sobre a pandemia. Disponível em: https://www.youtube.com/watch?v=T_kl-EMGkOw. Acesso em: 14 mai. 2020.

Twitter. Jair M. Bolsonaro. Disponível em: https://twitter.com/jairbolsonaro. Acesso em: 14 mai. 2020.

UOL. Leia o pronunciamento do presidente Jair Bolsonaro na íntegra. Disponível em: https://noticias.uol.com.br/politica/ultimas-noticias/2020/03/24/leia-opronunciamento-do-presidente-jair-bolsonaro-na-integra.htm. Acesso em: 14 mai. 2020.

\section{Referências}

ARISTÓTELES. Política. Tradução: Roberto Leal Pereira. São Paulo: Martins Fontes, 1998.

AJZENMAN, Nicolás; CAVALCANTI, Tiago; DA MATA, Daniel. More than words: leaders' speech and risky behavior during a pandemic. Social Science Research Network. 2020. Disponível em: https://ssrn.com/abstract=3582908. Acesso em: 14 mai. 2020.

BAUDILLARD, Jean. Simulacros e simulações. Tradução: Maria João da Costa Pereira. Lisboa: Relógio D’Água, 1991.

CARVALHO, José Murilo. Formação das almas: o imaginário da República do Brasil. São Paulo: Companhia das Letras, 1999.

CHARAUDEAU, Patrick. Discurso político. Tradução: Dílson Ferreira da Cruz e Fabiana Komesu. São Paulo: Contexto, 2008.

FRAGA, Vitor Galvão. Os três tipos de dominação legítima de Max Weber. Revista Jus Navigandi, Teresina, ano 18, n. 3791, 2013. Disponível em: https://jus.com.br/artigos/25863. Acesso em: 20 mai. 2020.

MARCUSCHI, Luiz Antônio. Cognição, linguagem e práticas interacionais. Rio de Janeiro: Lucerna, 2007.

MARQUES SILVA, Alexandre. A imagem por trás do mito: estratégias discursivas e construção do ethos no discurso político presidencial. 2010. Dissertação (Mestrado 
em Letras) - Faculdade de Filosofia, Letras e Ciências Humanas, Universidade de São Paulo, 2010.

MARQUES SILVA, Alexandre. Há'u Timoroan: a construção discursiva das identidades leste-timorenses. 2018. Tese (Doutorado em Letras) - Faculdade de Filosofia, Letras e Ciências Humanas, Universidade de São Paulo, 2018.

PERELMAN, Chaïm; OLBRECHTS-TYTECA, Lucie. Tratado da argumentação: a nova retórica. Tradução: Maria Ermantina Galvão G. Pereira. São Paulo: Martins Fontes, 1999 [1958].

WEBER, Max. Economia e sociedade: fundamentos da sociologia compreensiva. Tradução: Regis Barbosa e Karen Elsabe Barbosa. São Paulo: Imprensa Nacional, 2004.

WILD, Bianca. Os tipos de dominação segundo Max Weber. Disponível em: https://edisciplinas.usp.br/pluginfile.php/4517244/mod_resource/content $/ 5 /$ Wild_Os\%2 oTipos\%20de\%20Domina\%C3\%A7\%C3\%A30\%20segundo\%20Max\%20Weber.pdf. Acesso em: 20 mai. 2020.

\section{Forma de citação sugerida conforme ABNT}

MARQUES SILVA, Alexandre. (Não) é só uma gripezinha: argumentação e realidade forjada nos pronunciamentos de Jair Bolsonaro sobre a covid-19. EID\&A - Revista Eletrônica de Estudos Integrados em Discurso e Argumentação, Ilhéus, n. 20, v. 2, p. 4-28, ago. 2020. http://dx.doi.org/10.47369/eidea-20-2-2736. 